\title{
sensors
}

ISSN 1424-8220

(C) 2007 by MDPI

Full Research Paper

www.mdpi.org/sensors

\section{Utilizing of Square Wave Voltammetry to Detect Flavonoids in the Presence of Human Urine}

\author{
Vojtech Adam ${ }^{1,2}$, Radka Mikelova ${ }^{3}$, Jaromir Hubalek ${ }^{4}$, Pavel Hanustiak ${ }^{5}$, \\ Miroslava Beklova ${ }^{5}$, Petr Hodek ${ }^{6}$, Ales Horna ${ }^{7}$, Libuse Trnkova ${ }^{4}$, Marie Stiborova ${ }^{6}$, \\ Ladislav Zeman ${ }^{2}$ and Rene Kizek ${ }^{1, *}$
}

1 Department of Chemistry and Biochemistry, Mendel University of Agriculture and Forestry, Zemedelska 1, CZ-613 00 Brno, Czech Republic

2 Department of Animal Nutrition and Forage Production, Faculty of Agronomy, Mendel University of Agriculture and Forestry, Zemedelska 1, CZ-613 00 Brno, Czech Republic

3 Department of Chemistry, Faculty of Science, Masaryk University, Kotlarska 37, CZ-611 37 Brno, Czech Republic

4 Department of Microelectronics, Faculty of Electrical Engineering and Communication, Brno University of Technology, Udolni 53, CZ-602 00 Brno, Czech Republic

5 Department of Veterinary Ecology and Environmental Protection, Faculty of Veterinary Hygiene and Ecology, University of Veterinary and Pharmaceutical Sciences, Palackeho 1-3, CZ-612 42 Brno, Czech Republic

6 Department of Biochemistry, Faculty of Science, Charles University, Albertov 2030, CZ-128 40 Prague, Czech Republic

7 Department of Food Engineering, Faculty of Technology, Tomas Bata University, CZ-762 72 Zlin, Czech Republic

* Author to whom correspondence should be addressed. E-mail: kizek@sci.muni.cz

Received: 10 September 2007 / Accepted: 17 October 2007 / Published: 19 October 2007

\begin{abstract}
About biological affecting of flavonoids on animal organisms is known less, thus we selected flavonoids, flavanones and flavones, and their glycosides, which were examined as potential inducers of cytochrome(s) P450 when administrated by gavages into experimental male rats. The study was focused on induction of CYP1A1, the major cytochrome P450 involved in carcinogen activation. The data obtained demonstrate the necessity of taking into account not only ability of flavonoids to bind to Ah receptor (induction factor) but also to concentrate on their distribution and metabolism (including colon microflora) in the body. After that we examined certain flavonoids as potential
\end{abstract}


inducers of cytochrome P450, we wanted to suggest and optimize suitable electrochemical technique for determination of selected flavonoids (quercetin, quercitrin, rutin, chrysin and diosmin) in body liquids. For these purposes, we selected square wave voltannetry using carbon paste electrode. Primarily we aimed on investigation of their basic electrochemical behaviour. After that we have optimized frequency, step potential and supporting electrolyte. Based on the results obtained, we selected the most suitable conditions for determination of the flavonoids as follows: frequency $180 \mathrm{~Hz}$, step potential $1.95 \mathrm{mV} / \mathrm{s}$ and phosphate buffer of $\mathrm{pH} 7$ as supporting electrolyte. Detection limits $(3 \mathrm{~S} / \mathrm{N})$ of the flavonoids were from units to tens of $\mathrm{nM}$ except diosmin, where the limit were higher than $\mu \mathrm{M}$. In addition, we attempted to suggest a sensor for analysis of flavonoids in urine. It clearly follows from the results obtained that flavonoids can be analysed in the presence of animal urine, because urine did not influence much the signals of flavonoids (recoveries of the signals were about $90 \%$ ).

Keywords: flavonoids, antioxidant, carbon paste electrode, square wave voltammetry, western blot analysis, cytochrome P450, cancer

\section{Introduction}

Flavonoids are a group of polyphenolic compounds widely distributed throughout the plant kingdom. They are characterized by the presence of two benzene rings that are linked by a 3-carbon bridge (to form chalcones) or by a pyrane or pyrone ring (Figure 1a). On the basis of the position of and the modifications to these rings, more than 4,000 flavonoids discovered to date can be classified into several classes, including chalcones, flavandiols, flavones, flavonols, flavanones, anthocyanins, catechins, and aurones [1-3]. Flavonoids mainly occur as aglycones (consisting of a benzene ring condensed with a six member ring which possesses a phenyl ring at the 2 position), glycosides (that carry one or more sugar residues on the ring) or methylated derivatives [4]. Existence of free aglycones is rare, but it was observed that concentration of free aglycones could increase under specific conditions (during technological processing at high temperatures and also in acidic medium) when hydrolysis of glycosides may proceed $[3,5]$.

Flavonoids have received considerable attention because of their beneficial effects as antioxidants in the prevention of human diseases such as cancer and cardiovascular diseases, and some pathological disorders of gastric and duodenal ulcers, allergies, vascular fragility, and viral and bacterial infections [6]. They contribute to the antioxidant properties of green vegetables, fruits, olive and soybean oils, red wine, chocolate, and teas [7]. Some flavonoids have been reported to possess a variety of biological activities, including antiallergic, antiinflammatory, antiviral, antiproliferative, and anticarcinogenic activities, in addition to having effects on mammalian metabolism [6-8]. Several mechanisms by which flavonoids play an important role in cytotoxicity have been identified. Antitumour activity of several flavonoids (pinostrobin, quercetin, myricetin, morin) is attributed to their efficiencies to inhibit topoisomerase I and II $[9,10]$. Flavonoids might slow down cell proliferation as a consequence of their binding to estrogen receptor [11]. On the other hand, certain flavonoids like some 
other xenobiotics, including 2,3,7,8-terachlorodibenzo-p-dioxin, can induce activity of cytochrome P450s [12], which are responsible for activation of carcinogens such as benzo[a]pyrene, 7,12dimethylbenz[a]anthracene, aflatoxin B1 and meat-derived heterocyclic aromatic amines [13]. The effect of different flavonoids on cytochrome P450s has been reviewed in [14].

A number of spectrophotometric methods for quantification of flavonoids in materials of different kind have been developed. These assays are based on different principles and are used to determine various structural groups present in the compounds of interest [15]. Electrophoretic and high performance liquid chromatographic techniques are used widely for both separation and quantification of them [16-22]. Nevertheless, electrochemical detection is an attractive alternative method for electroactive species detection, because of its inherent advantages of simplicity, ease of miniaturization, high sensitivity and relatively low cost [23-45]. Thus, electrochemical methods such as differential pulse, cyclic and square wave voltammetry have been intensively utilizing for analysis of certain flavonoids [46-60].

Due to high abundance of flavonoids in human diet, we decided not only to optimize the square wave voltammetry for the detection of quercetin, quercitrin, rutin, chrysin and diosmin at $\mathrm{nM}$ level but also to examine them as potential inducers of cytochrome(s) at male rats.

\section{Experimental Section}

\subsection{Chemicals}

$\beta$-naphthoflavone, diosmin, chrysin, quercetin dehydrate, flavone, naringin, naringenin, hesperetin, hesperidin, baicalin, Freund's adjuvants, polyethylene glycol 6000, rabbit anti-chicken IgY-alkaline phosphatase conjugate, 5-bromo-4-chloro-3-indolylphosphate/nitrobluetetrazolium (BCIP/NBT) and $\mathrm{NaH}_{2} \mathrm{PO}_{4}$ were purchased from Sigma-Aldrich Chemical Corp. (St. Louis, MO, USA). Rutin trihydrate and quercitrin dihydrate were from Roth $\mathrm{GmbH}$ (Karlsruhe, Germany); PVDF membrane from Millipore (Bedford, MA, USA), bicinchoninic acid from Pierce (Rockford, IL, USA) and $\mathrm{Na}_{2} \mathrm{HPO}_{4}$ from Merck (Darmstadt, Germany). Other chemicals used were purchased from Sigma-Aldrich unless noted otherwise. Stock standard solutions of the flavonoids were prepared by ACS water (SigmaAldrich, USA) and stored in the dark at the temperature of $-20{ }^{\circ} \mathrm{C}$. Working standard solutions were prepared daily by dilution of the stock solutions. The $\mathrm{pH}$ value was measured using $\mathrm{pH}$ meter WTW inoLab (Weilheim, Germany). The pH-electrode (SenTix- H, pH 0-14/3M KCl) was regularly calibrated by set of WTW buffers (Weilheim, Germany).

\subsection{Electrochemical measurements}

Electrochemical measurements were performed with AUTOLAB Analyser (EcoChemie, Netherlands) connected to VA-Stand 663 (Metrohm, Switzerland), using a standard cell with three electrodes. The working electrode was a carbon paste electrode, the reference electrode an $\mathrm{Ag} / \mathrm{AgCl} / 3 \mathrm{M} \mathrm{KCl}$ electrode and the auxiliary electrode a graphite electrode. Phosphate buffer $(0.1 \mathrm{M}$ $\mathrm{NaH}_{2} \mathrm{PO}_{4}+0.1 \mathrm{M} \mathrm{Na}_{2} \mathrm{HPO}_{4}, \mathrm{pH} 7.0$ ) was used as supporting electrolyte. For smoothing and baseline correction the software GPES 4.9 supplied by EcoChemie was employed. All experiments were carried out at room temperature. Square wave voltammetric parameters were as follows: initial 
potential $0.0 \mathrm{~V}$, end potential $1.2 \mathrm{~V}$, pulse amplitude $49.85 \mathrm{mV}$. Step potential and frequency have been optimized, for more details see "Results and Discussion" section.

\subsection{Preparation of carbon paste electrode}

The carbon paste (about $0.5 \mathrm{~g}$ ) was made of $70 \%$ graphite powder (Sigma-Aldrich) and $30 \%$ mineral oil (Sigma-Aldrich; free of DNase, RNase, and protease). This paste was housed in a Teflon body having a 2.5-mm-diameter disk surface. Prior to measurements, an electrode surface was renewed by polishing with a soft filter paper [26,61].

\subsection{Preparation of human urine}

Human urine (obtained from healthy laboratory staff) was filtered through a Teflon disc filter $(0.45$ $\mu \mathrm{m}$ and $13 \mathrm{~mm}$ diameter, Alltech Associates, Deerfield, Il, USA) and 1,000 times diluted with phosphate buffer before measurements. We added quercetin, quercitrin, rutin and diosmin at 5, 7.5 and $10 \mu \mathrm{M}$ to 1,000 times dilute solution of human urine. As for diosmin, we used the followed concentrations: 300,400 and $500 \mu \mathrm{M}$.

\subsection{Animal treatment and preparation of microsomes}

Rat males divided into groups ( 3 animals) were treated by gavages with tested flavonoids (60 $\mathrm{mg} / \mathrm{kg}$ ) or sunflower oil (vehiculum) for 3 consecutive days. From livers and colons microsomal fractions were prepared by differential centrifugation as described elsewhere [62]. Protein concentrations were assessed using the bicinchoninic acid protein assay [63]. The concentration of CYP was estimated according to Omura and Sato [64]. All preparations were stored in small aliquots in liquid nitrogen prior to use.

\subsection{Preparation of anti-rat CYP1A1}

Leghorn chickens were immunized subcutaneously ones a week for three consecutive weeks by rat recombinant CYP1A1 (0.1 mg/animal) emulsified in complete Freund's adjuvant for the first injection and in incomplete one for boosters. Immunoglobulin fraction was isolated from pooled egg yolks as described by Polson et al. [65,66] using fractionation by polyethylene glycol 6000, and antibody was partially purified by an affinity chromatography [67].

\subsection{Western blot analysis of hepatic and colon microsomes}

Using Western blotting with specific anti-CYP1A1 antibodies induction of respective cytochrome(s) P450 was determined in microsomal samples of the liver and colon tissues prepared of rat exposed to tested flavonoids [68]. Molecular weight standards (SigmaMarker), liver and colon (7.5 $\mu \mathrm{g} / \mathrm{well}$ ) microsomal proteins were electrophoretically separated on SDS-PAGE using 7.5\% separation gel and then electro-transferred from the gel to a PVDF membrane on a semi-dry blot apparatus (Biometra, Germany) using $0.8 \mathrm{~mA} / \mathrm{cm}^{2}$ for $10 \mathrm{~min}$. and $2.0 \mathrm{~mA} / \mathrm{cm}^{2}$ for $45 \mathrm{~min}$. Membrane was then incubated at $4{ }^{\circ} \mathrm{C}$ overnight with $3 \%$ skim milk solution in PBS containing $0.3 \%$ Triton X100 (PBSM) to block unoccupied membrane binding sites. Afterwards, the membrane was cut into two parts and the 
first one incubated for 2 hrs under shaking with the preimmune antibody, the second one with the specific antibody. For detection of cytochrome(s) P4501A chicken antibodies were diluted to $20 \mu \mathrm{g} / \mathrm{ml}$ of PBSM. After washing membranes were individually incubated (1 hr) with the secondary antibody, rabbit anti-chicken IgY-alkaline phosphatase conjugate, diluted 2000 times with PBSM. After washing with PBSM and PBS, the membranes were developed with BCIP/NBT substrate.

\subsection{Statistical analysis}

STATGRAPHICS ${ }^{\circledR}$ (Statistical Graphics Corp ${ }^{\circledR}$, USA) was used for statistical analyses. Results are expressed as mean \pm S.D. unless noted otherwise. Differences with $p<0.05$ were considered significant.

\section{Results}

\subsection{Biological affecting of certain flavonoids on rats}

About biological affecting of flavonoids on animal organisms is known less, thus we selected flavonoids, flavanones and flavones, and their glycosides, which were examined as potential inducers of cytochrome(s) P450 (CYP) when administrated by gavages into experimental male rats. The study was focused on induction of CYP1A1, the major cytochrome P450 involved in carcinogen activation. Enhanced expression of this enzyme in colon tissue might be responsible for increasing incidence of colorectal carcinoma found in humans. There is a plenty of experimental data available in the literature dealing with the induction effect of flavonoids in various artificial systems (e.g. cell cultures), however, results are frequently contradictory possible because of the inadequate system used. The goal of the present work is a direct evidence of flavonoid induction of CYP1A1 in colon after flavonoid intake which is identical to the human exposure. Western blotting of colon and liver microsomal samples of $\beta$-naphthoflavone ( $\beta$-NF) treated rats shows that $\beta$-NF, known CYP1A1 (used as a positive control), is effective inducer for both tissues even when administered by gavages (see Figure 1).

Similarly, natural aglycons, chrysine, and quercetin and rutinoside, diosmin, caused in both tissues CYP1A1 induction. As glycosides are believed not to be absorbed from the colon microbial glycosidases are probable involved diosmetin (aglycone) formation. When comparing CYP1A1 induction in liver and colon tissues by other flavonoids shown in Figure 1A,B, it is clear that none of flavanones used (hesperetin, hesperidin) as well as flavone, baicalin (glucuronide) effected CYP1A1 expression. Of typical citrus flavonoids, naringin and naringenin (aglycone), the only induction was determined in the case of naringenin (aglycone) in the colon. Surprisingly, flavone (flavonoid lacking hydroxyl or methoxyl groups) was not efficient inducer in colon while the increased CYP1A1 expression was detected in liver. This observation is in accordance with the assumption that less polar flavonoids are freely passing membrane barrier and thus they are absorbed from colon to blood circulation. After metabolic conversion of flavone in liver (multiple hydroxylation) it might serve as CYP1A1 inducer like chrysin (5,7-dihydroxyflavone). These data demonstrate the necessity of taking into account not only ability of flavonoids to bind to Ah receptor (induction factor) but also to concentrate on their distribution and metabolism (including colon microflora) in the body. 


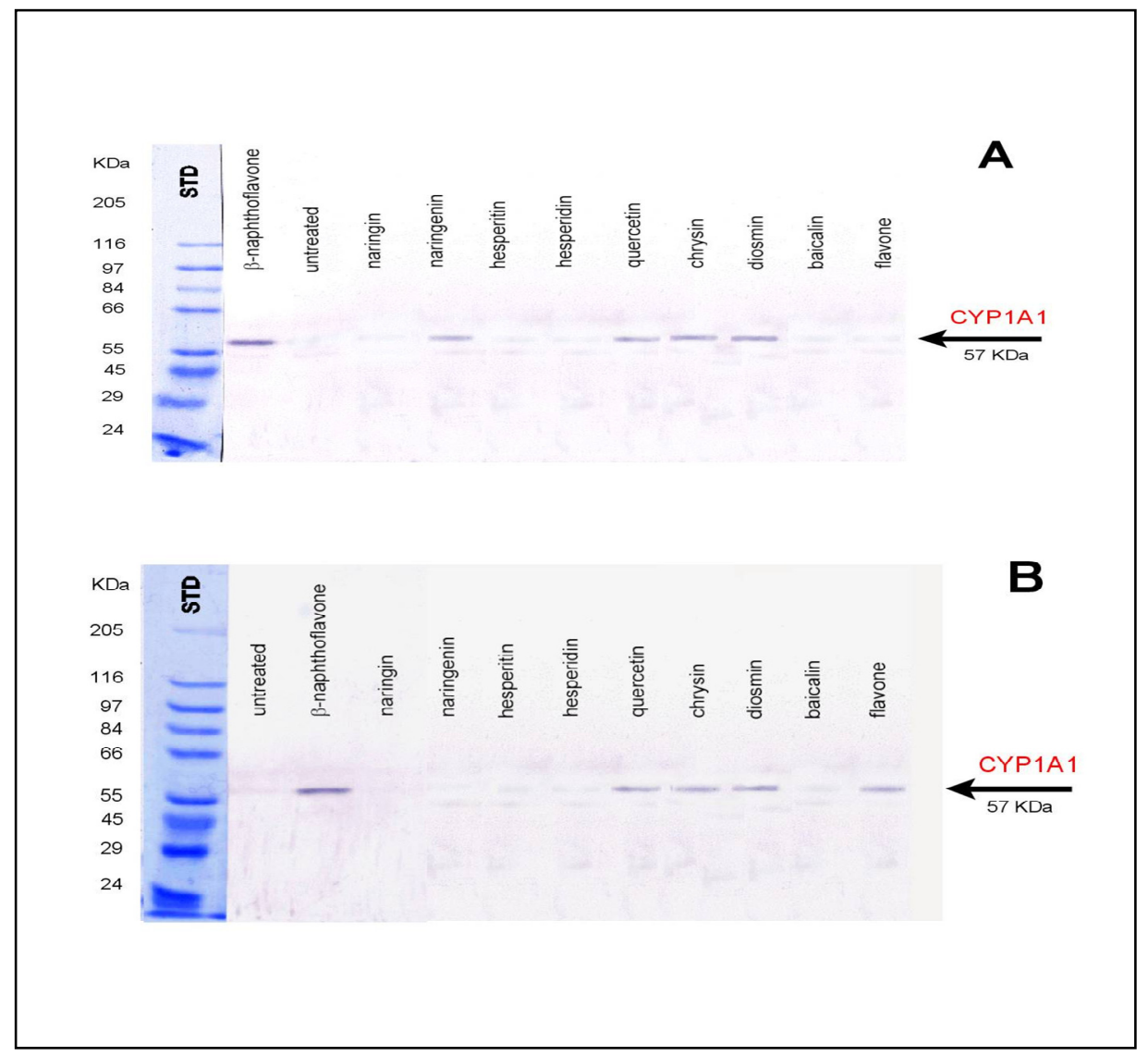

Figure 1. Immunodetection of CYP1A1 in colon (A) and liver $(\mathbf{B})$ microsomes from flavonoid treated rats. Electrophoresed microsomal proteins $(7.5 \mu \mathrm{g} /$ well $)$ were transferred to Immobilon-P membrane and probed with antibody against CYP1A1.

\subsection{Electroanalytical analysis of flavonoids}

After that we examined certain flavonoids as potential inducers of cytochrome P450, we wanted to suggest and optimize suitable electrochemical technique for determination of selected flavonoids (quercetin, quercitrin, rutin, chrysin and diosmin) in body liquids. It is common knowledge that phenolic compounds dissolve poorly in polar solvents (water) in comparison with non-polar ones (methanol), where these compounds have several times higher solubility. Thus, we wanted to select a suitable solvent where the solubility of compounds of interest would be highest. Methanol was selected as the most suitable solvent for these purposes. Recently we have found out that presence of an organic solvent markedly decreased height of current responses of compounds of interest [69-71]. Thus, we suggested that content of organic solvent in the supporting electrolyte $(2 \mathrm{ml})$ did not exceed $0.1 \%(v / v)$, which did not influence electrochemical determination of compounds of interest.

Recently, several papers, where the authors utilized glassy carbon electrode for determination of phenolic compounds, were published [46-48,58]. Here, we utilized square wave voltammetry for determination of quercetin, quercitrin, rutin, chrysin and diosmin using carbon paste electrode due to easier renewing of the electrode surface by polishing with a soft filter paper in comparison with glassy carbon electrodes (Figure 2). 


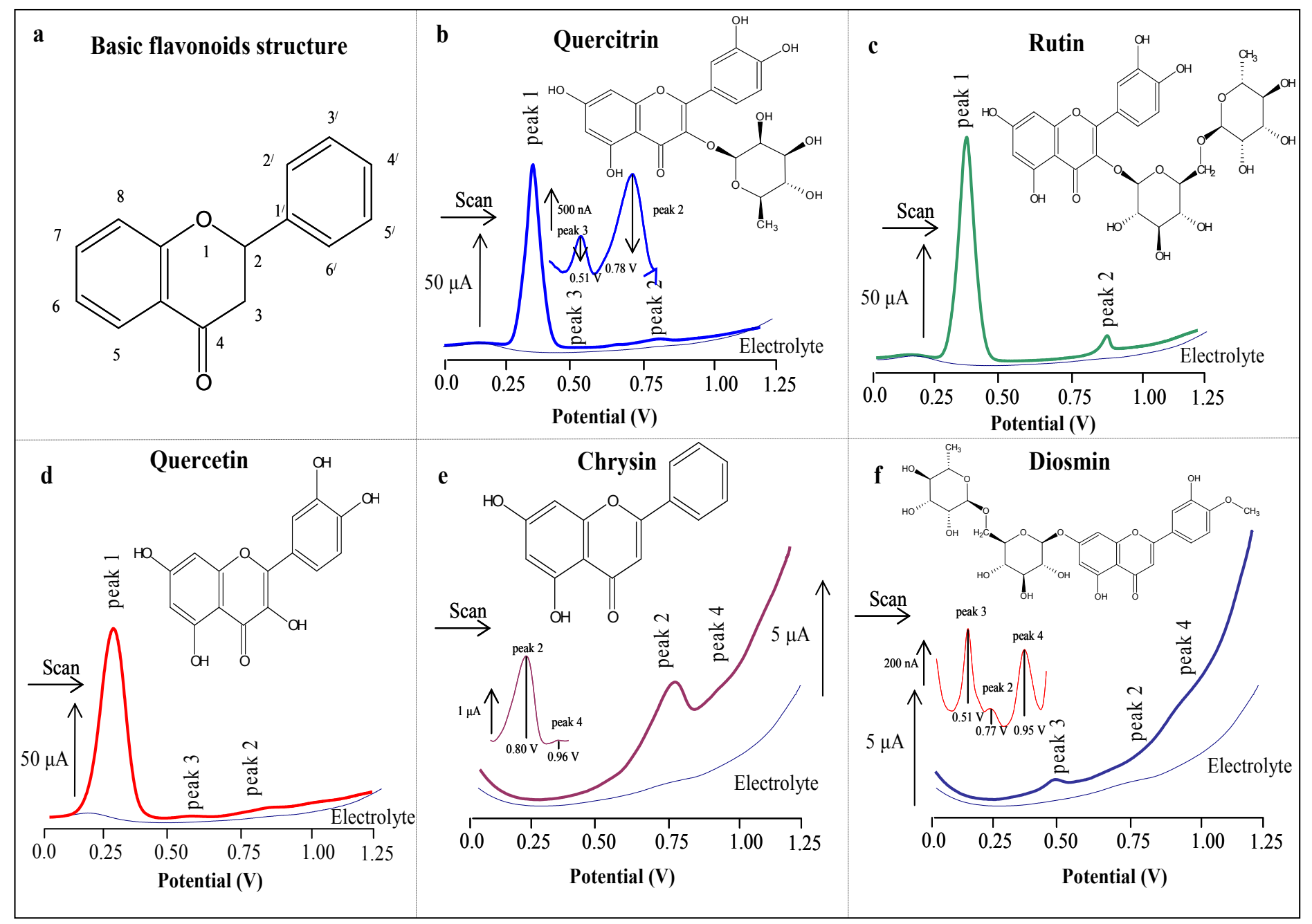

Figure 2. Flavonoid structure made of two benzene rings linked by heterocyclic pyrane (a). Squarewave voltammograms of the flavonoids $(10 \mu \mathrm{M})$ and their structures - quercitrin (b), rutin (c), quercetin (d), chrysin (e) and $100 \mu \mathrm{M}$ of diosmin (f). Square wave voltammetric parameters were as follows: initial potential $0.0 \mathrm{~V}$, end potential $1.2 \mathrm{~V}$, pulse amplitude $49.85 \mathrm{mV}$, step potential $1.5 \mathrm{mV}$, and frequency $100 \mathrm{~Hz}$. Phosphate buffer $\left(0.1 \mathrm{M} \mathrm{NaH}_{2} \mathrm{PO}_{4}+0.1 \mathrm{M} \mathrm{Na}_{2} \mathrm{HPO}_{4}, \mathrm{pH} 7.0\right)$ was used as a supporting electrolyte. For other details see Materials and Methods section.

\subsubsection{Basic electrochemical behaviour of flavonoids measured on the surface of carbon paste electrode}

Square wave voltammograms of the flavonoids measured in the presence of $0.1 \mathrm{M}$ phosphate buffer are shown in Figs. 2b-f. Quercetrin, quercitrin and diosmin gave three oxidation signals, but rutin and chrysin only two. Brett described that peaks 1 and 2 associates with oxidation of oxidation of hydroxyl group in position 7 of flavonoids structure [46]. Besides that, we observed two other peaks (peaks 3 and 4, Figs. 2b,d,e,f), which could corresponds to oxidation of hydroxyl group in position 7 of flavonoids structure [50]. In spite of that the analyzed flavonoids give signals corresponding to oxidation of the same groups in their structure, their potentials differ markedly $[48,59,60]$. We observed that peak 1 of quercetin $(0.25 \mathrm{~V})$ had potential shifted about $100 \mathrm{mV}$ in comparison with peak 1 belonging to quercitrin $(0.35 \mathrm{~V})$. This shift probably relates with presence of saccharide group 
in the structure of quercitrin in comparison with "non-saccharide" structure of quercetin. Peak 2 described at both chrysin and diosmin is thought to be the same, but the potentials differ again. This shift could be also associated with presence of disaccharide group in the structure of diosmin (Figure 2).

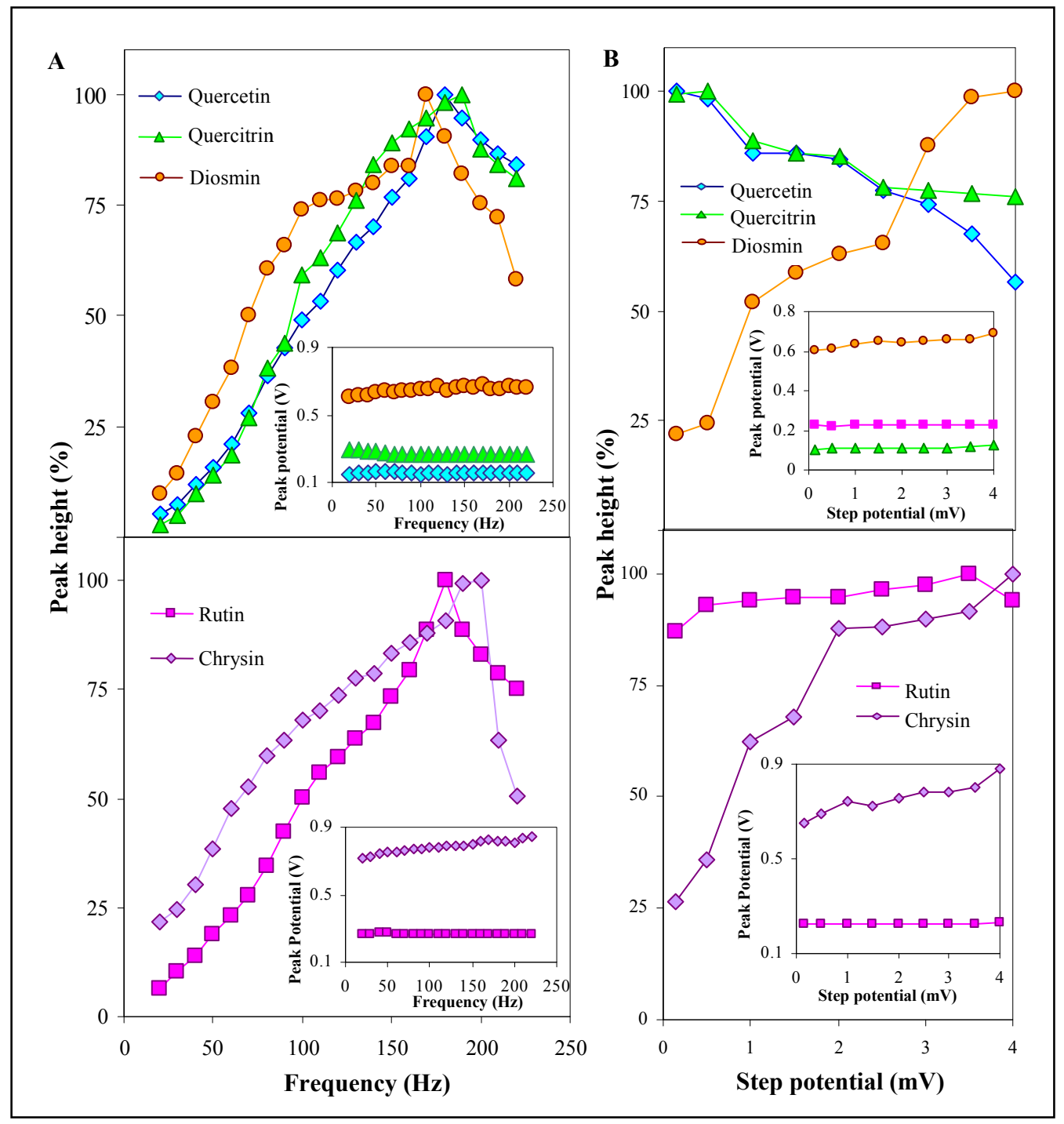

Figure 3. Influence of different frequencies (A and inset) and step potentials (B and inset) on peak heights and potentials of the flavonoids. For other details see Figure 2.

3.2.2 Influence of frequency, step potential and supporting electrolyte on SWV determination of flavonoids

As soon as we described basic electrochemical behaviour of the analyzed flavonoids measured on the surface of carbon paste electrode by SWV, we decided to optimize parameters (frequency and step potential) of the voltammetric method used. For evaluation of results obtained the signals of single flavonoids have been selected as follows: peak 1 for rutin, quercetin and quercitrin, and peak 2 for chrysin and diosmin. Influence of frequency has been studied within the range from 20 to $220 \mathrm{~Hz}$ (Figure 3A). The signals of flavonoids increased with increasing frequency up to $180-190 \mathrm{~Hz}$, and then sharp decrease of height of diosmin and rutin peaks followed. This marked change could be 
associated with structural formulas of rutin and diosmin, because both of them have disaccharide groups in their structure, where higher frequency could decrease electroactivity of positions need to oxidize.

In addition, height of peaks of rutin, quercetin and quercitrin decreased more slightly with frequency higher than $190 \mathrm{~Hz}$, whereas their potentials did not change much within whole studied range. Chrysin and diosmin peaks sifhted to more positive potentials with increasing frequency (insets in Figure 3A).We used frequency of $150 \mathrm{~Hz}$ for following analysis, because most of all compounds of interest gave the highest responses there. Moreover, we were interested in the issue how do these compounds behave with increasing step potential from 0.15 to $4 \mathrm{mV}$ (per $0.5 \mathrm{mV}$ ). The increasing step potential caused decrease in peaks height of quercetin and quercitrin, whereas rutin ones did not change much (Figure 3B). Chrysin and diosmin behave very similar again, whereas height of their peaks increased with increasing step potential markedly. Dependences of potentials of the studied flavonoids on step potential was similar shape as the frequency dependences (insets in Figure 3B). Based on the results obtained, step potential of $1.95 \mathrm{mV}$ was the most suitable for following purposes.

The optimization of flavonoids determination proceeded with selection of supporting electrolyte and its $\mathrm{pH}$. We wanted to study a broad range of $\mathrm{pH}$ from acidic to basic, thus, we used BrittonRobinson buffer within the range from $\mathrm{pH} 2$ to 8 (Figure 4A). The highest peaks of quercetin and diosmin were observed at $\mathrm{pH} 4$, and then the signals markedly decreased up to $\mathrm{pH} 8$, where the height of diosmin peak came up to units of percents in comparison with the highest ones and peak of quercetin did not detectable. In addition, rutin and quercitrin gave the highest signal at $\mathrm{pH} 2$ and then decreased within the whole range of higher $\mathrm{pH}$ values. The electrochemical behaviour of chrysin differed markedly from other ones. The current response of the chrysin peak increased with increasing $\mathrm{pH}$ up to 7 and then decreased slightly (Figure 4A). This phenomenon probably relates with basicity of this flavonoid $[48,58,72]$. Peaks of the flavonoids shifted to more negative potentials with increasing $\mathrm{pH}$ (inset in Figure 4A). It clearly follows from the results obtained that acidic pHs is suitable for analysis of quercetin, quercitrin, rutin and chrysin, but the basic $\mathrm{pHs}$ for diosmin analysis. In addition, we were interested in the issue how can different buffers influence the analysis of the flavonoids. Thus we used acetate $(\mathrm{pH} \mathrm{4)}$ and phosphate ( $\mathrm{pHs} \mathrm{6,7}$ and 8) buffers. The results obtained have been compared with analysis in the presence of Britton-Robinson buffer (Figure 4B). It clearly follows from the results obtained that acetate buffer is not suitable for determination of compounds of interest. It clearly follows for the results obtained that rutin, quercetin, quercitrin and chrysin gave the highest signals in the presence of phosphate buffer and diosmin in the presence of Britton-Robinson buffer. In spite of low current response of diosmin peaks in the presence of phosphate buffer, we decide to use it for following analysis of the flavonoids. Thus, more comprehensive investigation of behaviour of them in the presence of this buffer had to be done. We choose $\mathrm{pH}$ range from 5.5 to 8 and observed the changes in heights and potentials of flavonoids' peaks (Figure 4C). The highest peaks of rutin and quercetin were obtained at pH 6 and then the peaks decreased slightly (up to $25 \%$ in comparison with the highest ones). The height of quercetin peak did not change much with increasing $\mathrm{pH}$ (about $10 \%$ ). In addition, diosmin peak decreased slightly up to $\mathrm{pH} 7$ and then markedly (the signal measured at $\mathrm{pH}$ 8 decreased for more than $60 \%$ in comparison with the highest signal obtained at $\mathrm{pH} 5$ ). In the case of chrysin, we observed very different behaviour in comparison with other studied flavonoids again. Its signal increased up to $\mathrm{pH} 7.5$ and then decreased about $20 \%$. Peaks of all compounds of interest 
shifted to more negative potentials with increasing $\mathrm{pH}$ (insets in Figure 4C). We were encouraged by the results obtained, because phosphate buffer of $\mathrm{pH} \mathrm{7,} \mathrm{which} \mathrm{was} \mathrm{the} \mathrm{most} \mathrm{suitable} \mathrm{for} \mathrm{determination}$ of the flavonoids, is also the most suitable for analysis of biological material.

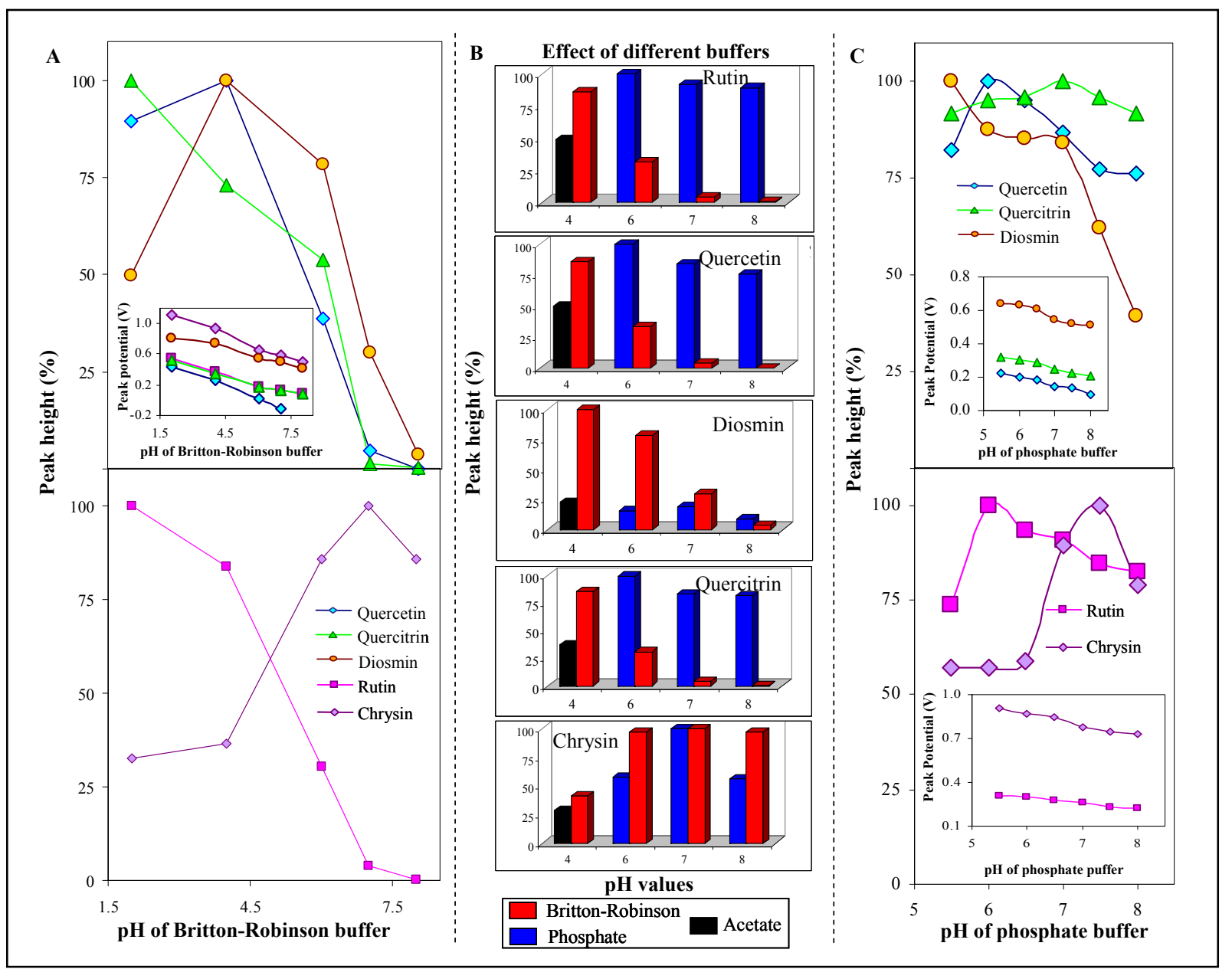

Figure 4. Influence of $\mathrm{pH}$ of Britton-Robinson buffer on peak heights and potentials of the flavonoids (A). Comparison of peak heights of the flavonoids measured in different buffers (B). Dependencies of peak heights and potentials of the flavonoids on different $\mathrm{pH}$ values of phosphate buffer $(\mathbf{C})$. Square wave voltammetric parameters were as follows: step potential $1.95 \mathrm{mV}$, and frequency $180 \mathrm{~Hz}$. For other details see Figure 2.

3.2.3 SWV study of influence of different flavonoids' concentrations on their electrochemical behaviour

Based on the results obtained, we selected the most suitable conditions for determination of the flavonoids as follows: frequency $180 \mathrm{~Hz}$, step potential $1.95 \mathrm{mV} / \mathrm{s}$ and phosphate buffer of $\mathrm{pH} 7$ as supporting electrolyte. We construed the dependences of the current responses on their concentrations (Figure 5A). The parameters of the calibration curves including R.S.D. are shown in Table 1. Detection limits $(3 \mathrm{~S} / \mathrm{N})$ of the flavonoids were from units to tens of $\mathrm{nM}$ except diosmin, where the limit were higher than $\mu \mathrm{M}$. This phenomenon relates with low current responses of this flavonoid in the supporting electrolyte used. A lower detection limit would be reached in the presence of BrittonRobinson buffer ( $\mathrm{pH}$ 2, Figure 4A). 

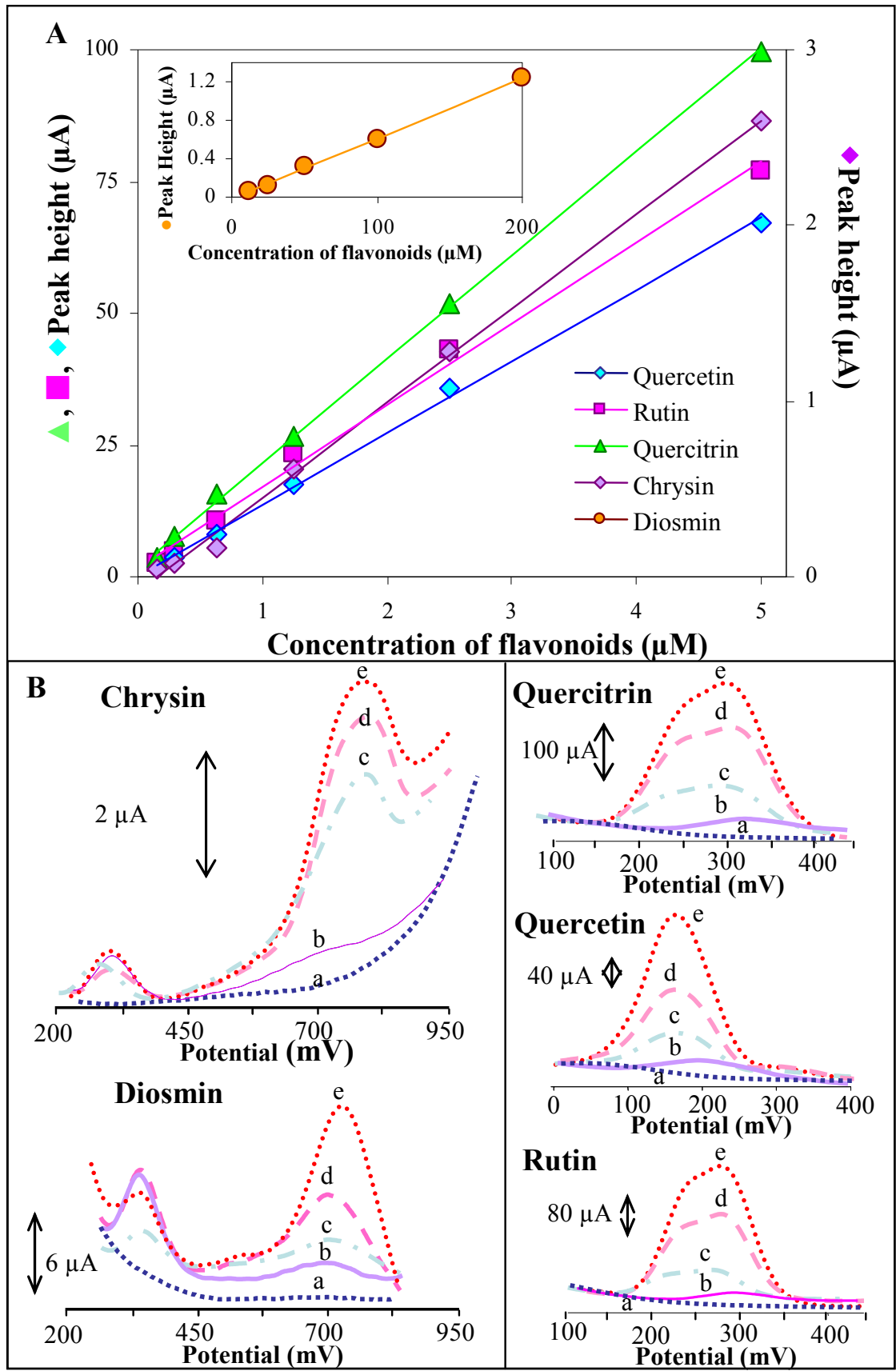

Figure 5. Dependencies of peak heights of the flavonoids on their different concentrations (A). Influence of human urine on signals of the flavonoids (B): a) electrolyte; b) 1,000 times dilute solution of human urine; c) $5 \mu \mathrm{M}$ of the flavonoids except diosmin $300 \mu \mathrm{M}$;

d) $7.5 \mu \mathrm{M}(400 \mu \mathrm{M})$; e) $10 \mu \mathrm{M}(500 \mu \mathrm{M})$. For other details see Figure 4 .

\subsection{An analysis of the flavonoids in the presence of urine}

Electrochemical techniques have many inherent advantages for determination of flavonoids and, moreover, can be used for distinguishing of their structure, as it has been shown during analysis of resveratrol [47]. In addition, they can be also used sensors. Here, we attempted to suggest a sensor for analysis of flavonoids in urine. Therefore, we were interested how will be the methods optimized above influenced by analysis of diluted human urine. A determination of the flavonoids in real samples 
has a crucial importance due to using of the technique for routine analysis. That also means, if the method optimized above will not be suitable for analysis of real samples, we could not use it in the following experiments. SW voltammograms of the flavonoids analysed in the presence of 1,000 times diluted human urine are shown in Figure 5B. It clearly follows from the results obtained that flavonoids can be analysed in the presence of animal urine, because urine did not influence much the signals of flavonoids (recoveries of the signals were about $90 \%$ ). Moreover, it seems that the urine itself give the low electrochemical signal. This signal did not correspond to flavonoids but to electroactive interferences, which could make an analysis more difficult.

Table 1. Validation data for the determination of flavonoids $(n=5)$.

\begin{tabular}{ccccccc}
\hline Flavonoid & Regression equation & $\begin{array}{c}\text { Concentration of } \\
\text { the flavonoid }(\boldsymbol{\mu M})\end{array}$ & ${ }^{\mathrm{a}} \mathbf{R}^{\mathbf{2}}$ & $\begin{array}{c}{ }^{\mathbf{b}} \mathbf{L O D} \\
(\mathbf{n M})\end{array}$ & $\begin{array}{c}{ }^{\mathbf{c}} \mathbf{L O Q} \\
(\mathbf{n M})\end{array}$ & $\begin{array}{c}{ }^{\mathrm{d}} \mathbf{R} . S . D . \\
(\mathbf{\%})\end{array}$ \\
\hline Quercetin & $\mathrm{y}=13.602 \mathrm{x}+0.1072$ & $0.15-5.0$ & 0.9988 & 10 & 33 & 3.7 \\
Quercitrin & $\mathrm{y}=19.678 \mathrm{x}+1.9359$ & $0.15-5.0$ & 0.9992 & 7 & 23 & 1.9 \\
Rutin & $\mathrm{y}=15.443 \mathrm{x}+1.5354$ & $0.15-5.0$ & 0.9944 & 9 & 30 & 3.6 \\
Chrysin & $\mathrm{y}=0.5367 \mathrm{x}-0.0841$ & $0.15-5.0$ & 0.9978 & 42 & 140 & 2.2 \\
Diosmin & $\mathrm{y}=0.0063 \mathrm{x}-0.0187$ & $12.5-200$ & 0.9995 & 2,663 & 8,877 & 3.5 \\
\hline
\end{tabular}

a: Correlation coefficient; b: Limit of Detections; c: Limit of Quantification; d: Relative standard deviation (\%)

\section{Conclusion}

Here, we have optimized the square wave voltammetry for the detection of quercetin, quercitrin, rutin, chrysin and diosmin at $\mathrm{nM}$ level and examined them as potential inducers of cytochrome(s) at male rats. We used modern analytical and molecular biological techniques to reach these goals. Moreover, the suggested electrochemical technique could be used for analysis body liquids such as urine.

\section{Acknowledgements}

We gratefully acknowledge by following grant agencies for financial supporting of this work: 303/06/0928 and 1M4635608802 and MSMT 6215712402 from The Czech Ministry of Education.

\section{References}

1. Taylor, L.P.; Grotewold, E. Flavonoids as developmental regulators. Curr. Opin. Plant Biol. 2005, 8, 317-323.

2. Woo, H.H.; Jeong, B.R.; Hawes, M.C. Flavonoids: from cell cycle regulation to biotechnology. Biotechnol. Lett. 2005, 27, 365-374.

3. Williams, C.A.; Grayer, R.J. Anthocyanins and other flavonoids. Nat. Prod. Rep. 2004, 21, 539573.

4. Di Carlo, G.; Mascolo, N.; Izzo, A.A.; Capasso, F. Flavonoids: Old and new aspects of a class of natural therapeutic drugs. Life Sci. 1999, 65, 337-353. 
5. Klejdus, B.; Sterbova, D.; Stratil, P.; Kuban, V. Identification and characterization of isoflavones in plant material by HPLC-DAD-MS tandem. Chem. Listy 2003, 97, 530-539.

6. Zand, R.S.R.; Jenkins, D.J.A.; Diamandis, E.P. Flavonoids and steroid hormone-dependent cancers. J. Chrom. B 2002, 777, 219-232.

7. Yao, L.H.; Jiang, Y.M.; Shi, J.; Tomas-Barberan, F.A.; Datta, N.; Singanusong, R.; Chen, S.S. Flavonoids in food and their health benefits. Plant Foods for Human Nutrition 2004, 59, 113-122.

8. Ren, W.Y.; Qiao, Z.H.; Wang, H.W.; Zhu, L.; Zhang, L. Flavonoids: Promising anticancer agents. Med. Res. Rev. 2003, 23, 519-534.

9. Sukardiman; Darwanto, A.; Tanjung, M.; Darmadi, M.O. Cytotoxic mechanism of flavonoid from Temu Kunci (Kaempferia pandurata) in cell culture of human mammary carcinoma. Clin. Hemorheol. Microcirc. 2000, 23, 185-190.

10. Constantinou, A.; Mehta, R.; Runyan, C.; Rao, K.; Vaughan, A.; Moon, R. Flavonoids as DNA Topoisomerase Antagonists and Poisons - Structure-Activity-Relationships. J. Nat. Prod. 1995, $58,217-225$.

11. Primiano, T.; Yu, R.; Kong, A.N.T. Signal transduction events elicited by natural products that function as cancer chemopreventive agents. Pharm. Biol. 2001, 39, 83-107.

12. Kohn, M.C.; Walker, N.J.; Kim, A.H.; Portier, C.J. Physiological modeling of a proposed mechanism of enzyme induction by TCDD. Toxicology 2001, 162, 193-208.

13. Omiecinski, C.J.; Remmel, R.P.; Hosagrahara, V.P. Concise review of the cytochrome P450s and their roles in toxicology. Toxicol. Sci. 1999, 48, 151-156.

14. Hodek, P.; Trefil, P.; Stiborova, M. Flavonoids-potent and versatile biologically active compounds interacting with cytochromes P450. Chem.-Biol. Interact. 2002, 139, 1-21.

15. Naczk, M.; Shahidi, F. Extraction and analysis of phenolics in food. J. Chromatogr. A 2004, 1054, 95-111.

16. Jac, P.; Polasek, M.; Pospisilova, M. Recent trends in the determination of polyphenols by electromigration methods. J. Pharm. Biomed. Anal. 2006, 40, 805-814.

17. Bedgood, D.R.; Bishop, A.G.; Prenzler, P.D.; Robards, K. Analytical approaches to the determination of simple biophenols in forest trees such as Acer (maple), Betula (birch), Coniferus, Eucalyptus, Juniperus (cedar), Picea (spruce) and Quercus (oak). Analyst 2005, 130, 809-823.

18. Smyth, W.F.; Brooks, P. A critical evaluation of high performance liquid chromatographyelectrospray ionisation-mass pectrometry and capillary electrophoresis-electrospray-mass spectrometry for the detection and determination of small molecules of significance in clinical and forensic science. Electrophoresis 2004, 10-11, 1413-1446.

19. Robards, K. Strategies for the determination of bioactive phenols in plants, fruit and vegetables. $J$. Chrom. A 2003, 1-2, 657-691.

20. Suntornsuk, L. Capillary electrophoresis of phytochemical substances. J. Pharmaceut. Biomed. 2002, 5, 679-698.

21. Franke, A.A.; Custer, L.J.; Arakaki, C.; Murphy, S.P. Vitamin C and flavonoid levels of fruits and vegetables consumed in Hawaii. J. Food Compos. Anal. 2004, 1, 1-35.

22. Escarpa, A.; Gonzales, M.C. An overview of analytical chemistry of phenolic compounds in foods. Crit. Rev. Anal. Chem. 2001, 2, 57-139. 
23. Kizek, R.; Trnkova, L.; Palecek, E. Determination of metallothionein at the femtomole level by constant current stripping chronopotentiometry. Anal. Chem. 2001, 73, 4801-4807.

24. Petrlova, J.; Potesil, D.; Mikelova, R.; Blastik, O.; Adam, V.; Trnkova, L.; Jelen, F.; Prusa, R.; Kukacka, J.; Kizek, R. Attomole voltammetric determination of metallothionein. Electrochim. Acta 2006, 51, 5112-5119.

25. Palecek, E.; Masarik, M.; Kizek, R.; Kuhlmeier, D.; Hassmann, J.; Schulein, J. Sensitive electrochemical determination of unlabeled MutS protein and detection of point mutations in DNA. Anal. Chem. 2004, 76, 5930-5936.

26. Masarik, M.; Kizek, R.; Kramer, K.J.; Billova, S.; Brazdova, M.; Vacek, J.; Bailey, M.; Jelen, F.; Howard, J.A. Application of avidin-biotin technology and adsorptive transfer stripping squarewave voltammetry for detection of DNA hybridization and avidin in transgenic avidin maize. Anal. Chem. 2003, 75, 2663-2669.

27. Palecek, E.; Kizek, R.; Havran, L.; Billova, S.; Fojta, M. Electrochemical enzyme-linked immunoassay in a DNA hybridization sensor. Anal. Chim. Acta 2002, 469, 73-83.

28. Labuda, J.; Buckova, M.; Heilerova, L.; Silhar, S.; Stepanek, I. Evaluation of the redox properties and anti/pro-oxidant effects of selected flavonoids by means of a DNA-based electrochemical biosensor. Anal. Bioanal. Chem. 2003, 376, 168-173.

29. Labuda, J.; Buckova, M.; Heilerova, L.; Caniova-Ziakova, A.; Brandsteterova, E.; Mattusch, J.; Wennrich, R. Detection of antioxidative activity of plant extracts at the DNA-modified screenprinted electrode. Sensors 2002, 2, 1-10.

30. Korbut, O.; Buckova, M.; Labuda, J.; Grundler, P. Voltammetric detection of antioxidative properties of flavonoids using electrically heated DNA modified carbon paste electrode. Sensors 2003, 3, 1-10.

31. Bukova, M.; Labuda, J.; Sandula, J.; Krizkova, L.; Stepanek, I.; Durackova, Z. Detection of damage to DNA and antioxidative activity of yeast polysaccharides at the DNA-modified screenprinted electrode. Talanta 2002, 56, 939-947.

32. Ovadekova, R.; Jantova, S.; Letasiova, S.; Stepanek, I.; Labuda, J. Nanostructured electrochemical DNA biosensors for detection of the effect of berberine on DNA from cancer cells. Anal. Bioanal. Chem. 2006, 386, 2055-2062.

33. Hodek, P.; Hanustiak, P.; Krizkova, J.; Mikelova, R.; Krizkova, S.; Stiborova, M.; Trnkova, L.; Horna, A.; Beklova, M.; Kizek, R. Toxicological aspects of flavonoid interaction with biomacromolecules. Neuroendocrinol. Lett. 2006, 27, 14-17.

34. Mikelova, R.; Hodek, P.; Hanustiak, P.; Adam, V.; Krizkova, S.; Havel, L.; Stiborova, M.; Horna, A.; Beklova, M.; Trnkova, L.; Kizek, R. Determination of isoflavones using liquid chromatography with electrochemical detection. Acta Chim. Slov. 2007, 54, 92-97.

35. Zitka, O.; Huska, D.; Krizkova, S.; Adam, V.; Chavis, G.J.; Trnkova, L.; Horna, A.; Hubalek, J.; Kizek, R. An investigation of glutathione-platinum(II) interactions by means of the flow injection analysis using glassy carbon electrode. Sensors 2007, 7, 1256-1270.

36. Vitecek, J.; Petrlova, J.; Adam, V.; Havel, L.; Kramer, K.J.; Babula, P.; Kizek, R. A fluorimetric sensor for detection of one living cell. Sensors 2007, 7, 222-238.

37. Trnkova, L.; Jelen, F.; Petrlova, J.; Adam, V.; Potesil, D.; Kizek, R. Elimination voltammetry with linear scan as a new detection method for DNA sensors. Sensors 2005, 5, 448-464. 
38. Supalkova, V.; Petrek, J.; Havel, L.; Krizkova, S.; Petrlova, J.; Adam, V.; Potesil, D.; Babula, P.; Beklova, M.; Horna, A.; Kizek, R. Electrochemical sensors for detection of acetylsalicylic acid. Sensors 2006, 11, 1483-1497.

39. Supalkova, V.; Petrek, J.; Baloun, J.; Adam, V.; Bartusek, K.; Trnkova, L.; Beklova, M.; Diopan, V.; Havel, L.; Kizek, R. Multi-instrumental investigation of affecting of early somatic embryos of Spruce by cadmium(II) and lead(II) ions. Sensors 2007, 7, 743-759.

40. Supalkova, V.; Huska, D.; Diopan, V.; Hanustiak, P.; Zitka, O.; Stejskal, K.; Baloun, J.; Pikula, J.; Havel, L.; Zehnalek, J.; Adam, V.; Trnkova, L.; Beklova, M.; Kizek, R. Electroanalysis of plant thiols. Sensors 2007, 7, 932-959.

41. Prasek, J.; Adamek, M.; Hubalek, J.; Adam, V.; Trnkova, L.; Kizek, R. New hydrodynamic electrochemical arrangement for cadmium ions detection using thick-film chemical sensor electrodes. Sensors 2006, 11, 1498-1512

42. Krizkova, S.; Beklova, M.; Pikula, J.; Adam, V.; Horna, A.; Kizek, R. Hazards of secondary bromadiolone intoxications evaluated using high-performance liquid chromatography with electrochemical detection. Sensors 2007, 7, 1271-1286.

43. Hubalek, J.; Hradecky, J.; Adam, V.; Krystofova, O.; Huska, D.; Masarik, M.; Trnkova, L.; Horna, A.; Klosova, K.; Adamek, M.; Zehnalek, J.; Kizek, R. Spectrometric and voltammetric analysis of urease - Nickel nanoelectrode as an electrochemical sensor. Sensors 2007, 7, 1238-1255.

44. Babula, P.; Huska, D.; Hanustiak, P.; Baloun, J.; Krizkova, S.; Adam, V.; Hubalek, J.; Havel, L.; Zemlicka, M.; Horna, A.; Beklova, M.; Kizek, R. Flow injection analysis coupled with carbon electrodes as the tool for analysis of naphthoquinones with respect to their content and functions in biological samples. Sensors 2006, 11, 1466-1482.

45. Adam, V.; Zehnalek, J.; Petrlova, J.; Potesil, D.; Sures, B.; Trnkova, L.; Jelen, F.; Vitecek, J.; Kizek, R. Phytochelatin modified electrode surface as a sensitive heavy metal ions biosensor. Sensors 2005, 5, 70-84.

46. Brett, A.M.O.; Ghica, M.E. Electrochemical oxidation of quercetin. Electroanalysis 2003, 15, 1745-1750.

47. Corduneanu, O.; Janeiro, P.; Brett, A.M.O. On the electrochemical oxidation of resveratrol. Electroanalysis 2006, 18, 757-762.

48. Janeiro, P.; Corduneanu, O.; Brett, A.M.O. Chrysin and (+/-)-taxifolin electrochemical oxidation mechanisms. Electroanalysis 2005, 17, 1059-1064.

49. Ghica, M.E.; Brett, A.M.O. Electrochemical oxidation of rutin. Electroanalysis 2005, 17, 313-318.

50. Janeiro, P.; Brett, A.M.O. Catechin electrochemical oxidation mechanisms. Anal. Chim. Acta 2004, 518, 109-115.

51. Malagutti, A.R.; Zuin, V.G.; Cavalheiro, E.T.G.; Mazo, L.H. Determination of rutin in green tea infusions using square-wave voltammetry with a rigid carbon-polyurethane composite electrode. Electroanalysis 2006, 18, 1028-1034.

52. Zeng, B.Z.; Wei, S.H.; Xiao, F.; Zhao, F.Q. Voltammetric behavior and determination of rutin at a single-walled carbon nanotubes modified gold electrode. Sens. Actuator B: Chem. 2006, 115, $240-$ 246.

53. Ensafi, A.A.; Hajian, R. Determination of rutin in pharmaceutical compounds and tea using cathodic adsorptive stripping voltammetry. Electroanalysis 2006, 18, 579-585. 
54. Timbola, A.K.; de Souza, C.D.; Giacomelli, C.; Spinelli, A. Electrochemical oxidation of quercetin in hydro-alcoholic solution. J. Braz. Chem. Soc. 2006, 17, 139-148.

55. Temerk, Y.M.; Ibrahim, H.S.M.; Schuhmann, W. Cathodic adsorptive stripping voltammetric determination of the antitumor drug rutin in pharmaceuticals, human urine, and blood serum. Microchim. Acta 2006, 153, 7-13.

56. Firuzi, O.; Lacanna, A.; Petrucci, R.; Marrosu, G.; Saso, L. Evaluation of the antioxidant activity of flavonoids by "ferric reducing antioxidant power" assay and cyclic voltammetry. Biochim. Biophys. Acta-Gen. Subj. 2005, 1721, 174-184.

57. Zoulis, N.E.; Efstathiou, C.E. Preconcentration at a carbon-paste electrode and determination by adsorptive-stripping voltammetry of rutin and other flavonoids. Anal. Chim. Acta 1996, 320, 255 261.

58. Janeiro, P.; Brett, A.M.O. Solid state electrochemical oxidation mechanisms of morin in aqueous media. Electroanalysis 2005, 17, 733-738.

59. Oliveira-Brett, A.M.; Diculescu, V.C. Electrochemical study of quercetin-DNA interactions: Part I. Analysis in incubated solutions. Bioelectrochemistry 2004, 64, 133-141.

60. Oliveira-Brett, A.M.; Diculescu, V.C. Electrochemical study of quercetin-DNA interactions - Part II. In situ sensing with DNA biosensors. Bioelectrochemistry 2004, 64, 143-150.

61. Kizek, R.; Masarik, M.; Kramer, K.J.; Potesil, D.; Bailey, M.; Howard, J.A.; Klejdus, B.; Mikelova, R.; Adam, V.; Trnkova, L.; Jelen, F. An analysis of avidin, biotin and their interaction at attomole levels by voltammetric and chromatographic techniques. Anal. Bioanal. Chem. 2005, 381, 1167-1178.

62. Stiborova, M.; Asfaw, B.; Frei, E.; Schmeiser, H.H.; Wiessler, M. Benzenediazonium Ion Derived from Sudan-I Forms an 8-(Phenylazo)Guanine Adduct in DNA. Chem. Res. Toxicol. 1995, 8, 489498.

63. Wiechelman, K.J.; Braun, R.D.; Fitzpatrick, J.D. Investigation of the Bicinchoninic Acid Protein Assay - Identification of the Groups Responsible for Color Formation. Anal. Biochem. 1988, 175, 231-237.

64. Omura, T.; Sato, R. The carbon monoxide-binding pigment of liver microsomes. I. Evidence for its hemoprotein nature. J. Biol. Chem. 1964, 239, 2370-2378.

65. Polson, A.; Vonwechmar, M.B.; Vanregenmortel, M.H.V. Isolation of Viral Igy Antibodies from Yolks of Immunized Hens. Immunol. Commun. 1980, 9, 475-493.

66. Polson, A.; Vonwechmar, M.B.; Fazakerley, G. Antibodies to Proteins from Yolk of Immunized Hens. Immunol. Commun. 1980, 9, 495-514.

67. Hodek, P.; Koblas, T.; Rydlova, H.; Kubickova, B.; Sulc, M.; Hudecek, J.; Stiborova, M. Chicken egg yolk as an excellent source of highly specific antibodies against cytochromes P450. Collect. Czech. Chem. Commun. 2004, 69, 659-673.

68. Guengerich, F.P.; Wang, P.; Davidson, N.K. Estimation of Isozymes of Microsomal CytochromeP-450 in Rats, Rabbits, and Humans Using Immunochemical Staining Coupled with Sodium Dodecyl-Sulfate Polyacrylamide-Gel Electrophoresis. Biochemistry 1982, 21, 1698-1706.

69. Klejdus, B.; Vacek, J.; Adam, V.; Zehnalek, J.; Kizek, R.; Trnkova, L.; Kuban, V. Determination of isoflavones in soybean food and human urine using liquid chromatography with electrochemical detection. J. Chrom. B 2004, 806, 101-111. 
70. Potesil, D.; Petrlova, J.; Adam, V.; Vacek, J.; Klejdus, B.; Zehnalek, J.; Trnkova, L.; Havel, L.; Kizek, R. Simultaneous femtomole determination of cysteine, reduced and oxidized glutathione, and phytochelatin in maize (Zea mays L.) kernels using high-performance liquid chromatography with electrochemical detection. J. Chrom. A 2005, 1084, 134-144.

71. Petrlova, J.; Mikelova, R.; Stejskal, K.; Kleckerova, A.; Zitka, O.; Petrek, J.; Havel, L.; Zehnalek, J.; Adam, V.; Trnkova, L.; Kizek, R. Simultaneous determination of eight biologically active thiol compounds using gradient elution-Liquid Chromatography with Coul-Array detection. J. Sep. Sci. 2006, 29, 1166-1173.

72. Jovanovic, S.V.; Steenken, S.; Tosic, M.; Marjanovic, B.; Simic, M.G. Flavonoids as Antioxidants. J. Am. Chem. Soc. 1994, 116, 4846-4851.

C 2007 by MDPI (http://www.mdpi.org). Reproduction is permitted for noncommercial purposes. 